\title{
Yes or No 2.0: Are Likert Scales Always Preferable to Dichotomous Rating Scales?
}

Pradeepkumar Bhupalam*

Associate Professor and Head, Department of Pharmacy Practice, Raghavendra Institute of Pharmaceutical Education and Research (RIPER), Chiyyedu Post, Ananthapuramu, Andhra Pradesh, INDIA.

\section{Correspondence}

Dr. Pradeepkumar Bhupalam

Associate Professor and Head, Department of Pharmacy Practice, Raghavendra Institute of Pharmaceutical Education and Research (RIPER), Chiyyedu Post, Ananthapuramu-515721, Andhra Pradesh, INDIA.

Phone no: +91 9985968504

Email: bhupalampradeep@gmail.com

DOI: 10.5330/ijpi.2019.3.27

\section{Sir,}

I read with interest the study by Mahmoud, et al. published in the 2019 Volume 9 Issue 1 of Int. J. Phrm. Investigation. ${ }^{1}$ A prospective cohort study was conducted by authors for a duration of three months from January to March 2018 with the aim to assess Knowledge and practice about use of medication amongst breast feeding women in eastern province of Saudi Arabia community. ${ }^{1}$ Authors prepared a self-administered questionnaire to gather the data from the contributors. The survey consisted of two sections. The first section comprised of items related to demographic information of the contributors. The second section knowledge and attitude about use of medication among breast feeding women. Participants' replies were documented based on a 2-point Likert scale of agreement. Authors recorded the responses of participants as 'Yes or No'. And these results were cautiously interpreted. Answering scale of two options, we need to keep in mind that it is not Likert-like scale, i.e. not an ordinal scale rather a nominal scale. I presume that dichotomous scale is suitable for the participant's responses like 'Yes or No'. An over-simplistic summary would be that, despite passionate statements made by psychometricians, there is no Yes or No answer to the apparent superiority of Likert-type scales for survey items. There are a variety of ways to lay these questions out on a questionnaire. ${ }^{2}$ When a question has two possible responses, dichotomous would be considered. Surveys often use dichotomous questions that ask for a Yes/No, True/ False or Agree/Disagree response.,

\section{REFERENCES}

\footnotetext{
1. Mahmoud SA, Ali MD, Ahmad A, Maghrabi AA, Harthi MA, Fattani NA Knowledge and Practice about use of Medication among Breast Feeding Women in Saudi Arabia: A Prospective Cohort Study. Int J Phrm Investigation. 2019;9(1):16-9.

2. https://www.socialresearchmethods.net/kb/questype.php.

3. https://www.surveycrest.com/blog/scales-or-yes-no-questions/.
} 